PNWD-3051

BNFL-RPT-039, Rev. 0

\title{
Active Waste Materials Corrosion and Decontamination Tests
}

\author{
M. J. Danielson \\ M. R. Elmore \\ S. G. Pitman
}

August 2000

Prepared for

BNFL, Inc.

under Contract W375-LC-98-4168

Battelle, Pacific Northwest Division

Richland, Washington 99352 


\section{DISCLAIMER}

This report was prepared as an account of work sponsored by an agency of the United States Government. Neither the United States Government nor any agency thereof, nor any of their employees, make any warranty, express or implied, or assumes any legal liability or responsibility for the accuracy, completeness, or usefulness of any information, apparatus, product, or process disclosed, or represents that its use would not infringe privately owned rights. Reference herein to any specific commercial product, process, or service by trade name, trademark, manufacturer, or otherwise does not necessarily constitute or imply its endorsement, recommendation, or favoring by the United States Government or any agency thereof. The views and opinions of authors expressed herein do not necessarily state or reflect those of the United States Government or any agency thereof. 


\section{DISCLAIMER}

Portions of this document may be illegible in electronic image products. Images are produced from the best available original document. 


\section{Summary and Conclusions}

Stainless steel alloys, $304 \mathrm{~L}$ and $316 \mathrm{~L}$, were corrosion tested in representative radioactive samples of three actual Hanford tank waste solutions (Tanks AW-101, C-104, AN-107). Both the 304L and 316L

exhibited good corrosion performance when immersed in boiling waste solutions. The maximum general corrosion rate was $0.015 \mathrm{~mm} / \mathrm{y}$ ( 0.60 mils per year). Generally, the $304 \mathrm{~L}$ had a slightly higher rate than the 316L. No localized attack was observed after 122 days of testing in the liquid phase, liquid/vapor phase, or vapor phase. Radioactive plate-out decontamination tests indicated that a 24-hour exposure to $1 \underline{\mathrm{M} \mathrm{HNO}} 3$ could remove about $99 \%$ of the radioactive components in the metal film when exposed to the C-104 and AN-107 solutions. The decontamination results are less certain for the AW-101 solution, since the initial contamination readings exceeded the capacity of the meter used for this test. 


\section{Contents}

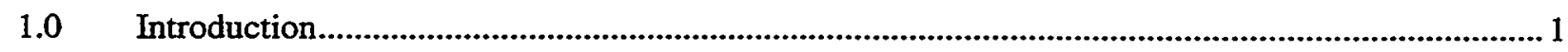

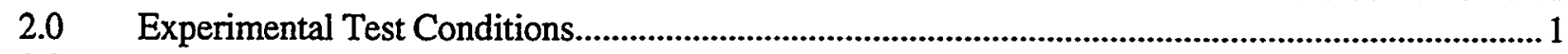

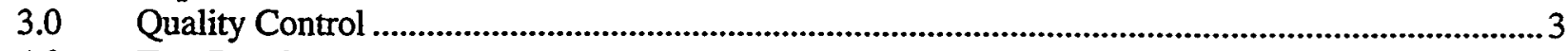

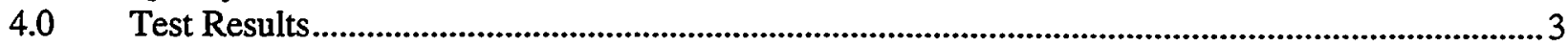

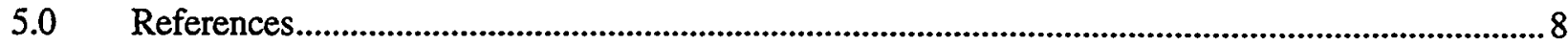




\section{Figures}

Figure A.1. Test Apparatus Set Up in the Contamination Area Hood .....................................................2

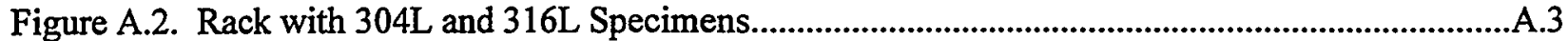

Figure A.3. Specimens After Removal From AN-107 Solution (316L Specimens on Left) ...................A.4

Figure A.4. Specimens After Removal From AW-101 Solution...................................................................5

Figure A.5. Specimens After Removal From C-104 Solution.....................................................................6

Figure A.6. AN-107 Specimens After Plate-Out Decontamination Tests .................................................7

Figure A.7. AW-101 Specimens After Plate-Out Decontamination Tests ...............................................8

Figure A.8. Specimens from Liquid Phase Exposure - AW-101 Solution Following Final

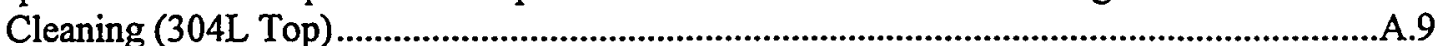

Figure A.9. Specimens from Liquid/Vapor Phase Exposure - AW-101 Solution Following Final Cleaning (304L Top Row)...

Figure A.10. Specimens from Vapor Phase (Noncondensing) Exposure - AW-101 Solution Following Final Cleaning (304L Top Row)

Figure A.11. Specimens from Vapor Phase (Condensing) Exposure - AW-101 Solution Following Final Cleaning (304L Top Row)

Figure A.12. Specimens from Liquid Phase Exposure-C-104 Solution Following Final Cleaning (304L Top Row)

Figure A.13. Specimens from Liquid/Vapor Phase Exposure-C-104 Solution Following Final Cleaning (304L Top Row)...

Figure A.14. Specimens from Vapor Phase (Noncondensing) Exposure - C-104 Solution Following Final Cleaning (304L Top Row).

Figure A.15. Specimens from Vapor Phase (Condensing) Exposure - C-104 Solution Following Final Cleaning (304L Top Row)

Figure A.16. Specimens from Liquid Phase Exposure - AN-107 Solution Following Final Cleaning (304L Top Row)

Figure A.17. Specimens from Liquid/Vapor Phase Exposure - AN-107 Solution Following Final Cleaning (304L Top Row)

Figure A.18. Specimens from Vapor Phase (Noncondensing) Exposure - AN-107 Solution Following Final Cleaning (304L Top Row).

Figure A.19. Specimens from Vapor Phase (Condensing) Exposure - AN-107 Solution Following Final Cleaning (304L Top Row)

\section{Tables}

Table 1. Compositions of Stainless Steel Alloys.......................................................................... 1

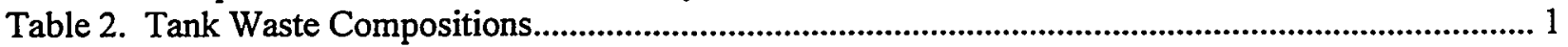

Table 3. Radioactive Tank Waste Test Solutions ...................................................................................... 2

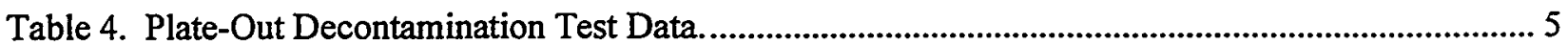

Table 5. Plate-Out Deposit Removal During the Decontamination Test .................................................6

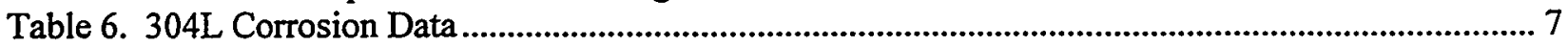

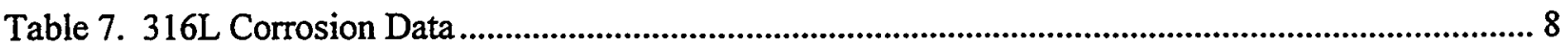




\subsection{Introduction}

Corrosion tests were conducted to support confirmation of the design basis, and help select materials of construction for the process vessels and equipment used to handle the radioactive feed going to the lowactivity waste (LAW) melter evaporator in the vitrification plant. This activity is also developing data on radionuclide plate-out on equipment in contact with the wastes, and decontamination of that equipment by soaking in nitric acid. Guidance for this work was provided by the River Protection Project - Waste Treatment Plant (RPP-WTP), Materials Corrosion, Erosion, and Plate-Out Test Specification, Revision 2, dated August 24, 1999 (BNFL 1999).

\subsection{Experimental Test Conditions}

Two stainless steel alloys (304L and 316L) were evaluated for corrosion resistance in three radioactive tank waste solutions from HanfordTanks AW-101, C-104, and AN-107. Table 1 shows the compositions of the two stainless steels. Table 2 shows the approximate compositions of the 3 tank waste solutions as tested. A plate-out decontamination test was subsequently used to determine the ability of a 24-hour soak in $1 \mathrm{M} \mathrm{HNO}_{3}$ solution to reduce the radiation levels from contaminated metal components exposed to tank wastes. This report contains the results of 4-month corrosion tests of alloy specimens exposed to boiling solutions and the results of 24-hour decontamination soak tests in $1 \underline{\mathrm{M}} \mathrm{HNO}_{3}$.

Table 1. Compositions of Stainless Steel Alloys

\begin{tabular}{|c|c|c|c|c|c|c|c|c|c|c|c|c|}
\hline \multirow{2}{*}{ Alloy } & \multicolumn{10}{|c|}{ Component Concentrations, wt\% } \\
\cline { 2 - 14 } & $\mathbf{C}$ & $\mathbf{M n}$ & $\mathbf{P}$ & $\mathbf{S}$ & $\mathbf{S i}$ & $\mathbf{C r}$ & $\mathbf{N i}$ & $\mathbf{M o}$ & $\mathbf{C u}$ & $\mathbf{C o}$ & Other & Other \\
\hline $316 \mathrm{~L}$ & 0.011 & 1.49 & 0.028 & 0.015 & 0.57 & 16.34 & 10.12 & 2.07 & 0.34 & 0.20 & $\begin{array}{c}0.06 \\
\mathrm{~N}\end{array}$ & $\begin{array}{c}\mathrm{Bal} \\
\mathrm{Fe}\end{array}$ \\
\hline $304 \mathrm{~L}$ & 0.029 & 1.52 & 0.023 & 0.001 & 0.36 & 18.06 & 8.86 & 0.29 & 0.17 & - & - & $\begin{array}{c}\mathrm{Bal} \\
\mathrm{Fe}\end{array}$ \\
\hline
\end{tabular}

Table 2. Tank Waste Compositions

\begin{tabular}{|l|c|c|c|c|c|c|c|c|}
\hline \multirow{2}{*}{$\begin{array}{l}\text { Tank } \\
\text { Waste }\end{array}$} & \multicolumn{8}{|c|}{ Component Concentrations, } \\
\cline { 2 - 9 } & $\mathbf{N a}$ & $\mathbf{F}$ & $\mathbf{C l}$ & $\mathbf{N O}_{\mathbf{2}}$ & $\mathbf{N O}_{3}$ & $\mathbf{O H}$ & $\mathbf{T I C}$ & TOC \\
\hline AW-101 & 9.0 & 0.07 & 0.12 & 2.1 & 2.5 & 4.0 & 0.2 & 0.1 \\
\hline AN-107 & 9.0 & 0.39 & 0.05 & 1.5 & 3.0 & 0.8 & 1.6 & 2.9 \\
\hline C-104 & 9.0 & NA & NA & NA & NA & NA & NA & NA \\
\hline
\end{tabular}

NA - not available

Immersion tests were carried out using the methods reported in ASTM procedures ASTM-G-31-72, Standard Practice for Laboratory Immersion Corrosion Testing for Metals and ASTM-G-1-90, Standard Practice for Preparing, Cleaning, and Evaluating Corrosion Test Specimens. 
The dimensions of the stainless steel test specimens were approximately $2.54 \times 1.27 \times 0.16 \mathrm{~cm}$ ( $1 \times 0.5 \times 1 / 16$ in.) with a $0.64-\mathrm{cm}(0.25$-in.) diameter hole in one end for mounting, giving a total area of approximately $7.6 \mathrm{~cm}^{2}\left(\sim 1.2 \mathrm{in}^{2}\right)$ for each specimen. The dimensions of each specimen were measured and recorded.

Each specimen was stamped with a unique identification number. Identification numbers started with 4-XX for the 304L material and 6-XX for the 316L material; the XX denotes the serial number. Before testing, the specimens were washed in a detergent solution, followed by a deionized (DI) water rinse and a high purity ethanol rinse, then air-dried and weighed to the nearest $0.1 \mathrm{mg}$.

The test apparatus (Figure A.1) consisted of three $500-\mathrm{mL}$ polypropylene containers for the three waste solutions with condensers located in the centers of the lids, Type- $K$ thermocouples (sheathed in Inconel 600 ) inserted into the liquid phase, and magnetic stirring bars. Each poly container was placed into a $3000-\mathrm{mL}$ Teflon vessel containing silicone oil to transfer heat to the polypropylene. Each Teflon vessel was placed into a snug-fitting resin kettle heater that sat on a magnetic stirrer for continuous agitation of the waste. The liquid phase test temperature was boiling $\left(-102^{\circ} \mathrm{C}\right)$, and a separate temperature controller (set to $105^{\circ} \mathrm{C}$ ) was used for each heater. A corrosion rack was constructed from corrosion-resistant titanium for each poly container. Two test specimens per alloy were immersed in the test solution, suspended at the liquid/vapor interface, suspended in the vapor space above the test solution (no condensation), and suspended under the reflux condenser in the vapor space (condensation). The specimens were insulated from each other and the rack with Teflon tubing and spacers. Figure A.2 shows specimens mounted on a rack.

The three radioactive test solutions were transferred from the 325 Building to Room 120 in the 329 Building, where the tests were carried out in a CA (contamination area) hood. The original wastes had been diluted during previous testing to mimic expected processing conditions and used to demonstrate waste treatment processes. As received, the solutions were too dilute to duplicate the original tank concentrations, and consequently, were slowly evaporated in open beakers until each was approximately $9 \mathrm{M} \mathrm{Na}$ in concentration. Table 3 gives some information on the tank waste solutions. Approximately $250 \mathrm{~mL}$ of solution were placed into each poly container at the start of the corrosion tests. The testing was started on January 19, 2000, and stopped May 22, 2000, for a total of 122 days of exposure. On approximately a weekly basis, the poly containers were lifted out of the silicone oil and visually inspected. As needed, deionized water was occasionally added during the test period to maintain solution levels in the poly containers.

Table 3. Radioactive Tank Waste Test Solutions

\begin{tabular}{|c|c|c|c|}
\hline Solution & Radioactivity $^{(\text {a) }}$ & $\begin{array}{c}\text { Pre-test } \\
\text { Evaporation }\end{array}$ & $\begin{array}{c}\text { Solution Observation } \\
\text { (after concentration) }\end{array}$ \\
\hline $\mathrm{C}-104$ & $1 \mathrm{MBq}$ & $1000 \mathrm{~mL} \rightarrow 250 \mathrm{~mL}$ & amber, clear \\
\hline $\mathrm{AW}-101$ & $5.6 \mathrm{GBq}$ & $500 \mathrm{~mL} \rightarrow 250 \mathrm{~mL}$ & yellow, clear \\
\hline $\mathrm{AN}-107$ & $13 \mathrm{GBq}$ & $700 \mathrm{~mL} \rightarrow 350 \mathrm{~mL}$ & brown, solids \\
\hline
\end{tabular}

(a) Activity values at contact before concentration from \#10798 Battelle Onsite Shipment Record (shipped from 325 Building to 329 Building on January 10, 2000). 
On May 22, 2000, the temperature controllers were shut off, and the system was allowed to partially cool. The racks of specimens were removed from each test solution, washed in DI water, washed in acetone, air dried, and visually examined and photographed. All specimens were still in place on the rack. The Ti racks were examined, and no corrosion of the racks was observed. Photographs of the specimens after exposure are shown in Figures A.3 through A.5.

The specimens were moved to Room 130 (329 Building), where an electronic balance is maintained in a CA hood. The radioactive plate-out decontamination tests were performed in this hood on the totally immersed specimens. First, the alpha and beta-gamma count rates were measured and recorded for each specimen (front side with ID number and back side). The sensor head was held $\sim 1 \mathrm{~cm}$ away from the specimen to avoid contamination of the radiation monitoring equipment. The background values were 0 $\mathrm{c} / \mathrm{m}$ (counts/minute) for alpha and $500 \mathrm{c} / \mathrm{m}$ for beta-gamma. The specimens were weighed and then soaked in $1.0 \mathrm{M} \mathrm{HNO}_{3}$ for 24 hours to determine the effectiveness of the acid treatment for removing the radioactive deposits. The specimens were strung on an alloy 600 wire with a Teflon spacer separating the metal specimens. After the 24-hour soak, the specimens were washed in DI water, washed in acetone, and air dried. Again, the alpha and beta-gamma count rates were determined for each immersed specimen, and the specimens were reweighed. The specimens from the AN-107 and AW-101 solutions were photographed. (An oversight resulted in the specimens of C-104 not being photographed.) The - experimental data for the plate-out tests are given in Tables 4 and 5, and the photographs are shown in Figures A.6 and A.7.

Many of the specimens were covered with a tenacious deposit that had to be removed before the corrosion rates could be determined. Specimens were cleaned by soaking in CP-9 cleaning solution ( $500 \mathrm{ml} \mathrm{DI}$ water $+500 \mathrm{ml}$ concentrated $\mathrm{HCl}+25 \mathrm{ml}$ formaldehyde) for a total of 30 minutes at ambient temperature) (Danielson and Pitman 2000). Weight loss measurements were taken on three blanks of each alloy to determine metal loss from just exposure to the cleaning solution. Those weight losses due to cleaning were: $0.0018 \mathrm{~g}$ for $304 \mathrm{~L}$, and $0.0002 \mathrm{~g}$ for $316 \mathrm{~L}$.

The weight loss of each test specimen was corrected for the loss due to the attack of the cleaning solution before the corrosion rate was calculated. The specimens were reweighed after cleaning. Each specimen was visually examined for localized attack, and a visual corrosion assessment was made. The specimens were then photographed in the cleaned condition. The experimental data with the calculated corrosion rates are shown in Tables 6 and 7. Photographs of the cleaned specimens are given in Figures A.8 through A.19.

\subsection{Quality Control}

This work was conducted in accordance with a BNFL-approved quality assurance plan that implements the requirements of 10 CFR 830.120. An approved Test Plan (TP-29953-070, Rev. 0) was written before the testing began.

\subsection{Test Results}

The corrosion rate data in Tables 5 and 6 indicate that both alloys have very low corrosion rates. Corrosion rates are given in millimeters per year $(\mathrm{mm} / \mathrm{y})$, as well as mils $(0.001 \mathrm{in}$.) per year (mpy). The $304 \mathrm{~L}$ stainless steel had a slightly higher corrosion rate than the $316 \mathrm{~L}$, although not a significant difference. The highest reported rate for both alloys was at the liquid/vapor interface in the AW-101 solution, an average of $0.0141 \mathrm{~mm} / \mathrm{y}(0.55 \mathrm{mpy})$ for the $304 \mathrm{~L}$ and $0.0135 \mathrm{~mm} / \mathrm{y}(0.53 \mathrm{mpy})$ for the $316 \mathrm{~L}$. 
Furthermore, there was no knifeline attack visible at the liquid/vapor interface, which is an indicator that the corrosion processes are not localized. A visual examination after the specimens were cleaned in CP-9 indicated no evidence of pitting, crevice attack, or any other form of localized attack.

The results of the decontamination test (24-hour soak in $1 \mathrm{M} \mathrm{HNO}$ ) are also given in Table 3. Radiation measurements are in $\mathrm{c} / \mathrm{m}$. The percent reduction values are a measure of the reduction in the initial beta/gamma readings due to the cleaning process. The front and back readings were added together for the calculation, and corrected for the background reading before calculating the percent reduction. The AW-101 solution resulted in beta/gamma levels that were above the maximum reading level of the instrument, preventing an accurate determination of the percent reduction from the initial reading. Consequently, for any measurement in which the instrument reading was off-scale, the percent reduction is prefixed with the $>$ sign, indicating that the calculated value is the minimum possible value. The data indicate that the radiation reduction is $>99 \%$ for the $\mathrm{C}-104$ and $\mathrm{AN}-107$ solutions. Alpha radiation was not measured in significant enough quantities to determine any reduction effect.

The weights of deposits removed from the specimens during the decontamination soak test are summarized in Table 4. The exposure to the AW-101 solution resulted in a deposit that was difficult to remove, particularly for the $304 \mathrm{~L}$ stainless (65\% removal). Figure A.7 shows that the specimens were covered with a thin black film after the decontamination soak. The deposits from the C-104 solution were - somewhat easier to remove, particularly for the $316 \mathrm{~L}$ stainless (87-91\% removal). Deposits from the AN-107 solution were the easiest to remove (97-100\% removal), which is substantiated by the shiny appearance of the specimens shown in Figure A.6. 
Table 4. Plate-Out Decontamination Test Data

\begin{tabular}{|c|c|c|c|c|c|c|c|c|c|c|c|}
\hline Specimen & Solution & $\mid \begin{array}{c}\text { Observation } \\
\text { Before } \mathrm{HNO}_{3}\end{array}$ & $\begin{array}{c}\text { Alpha } \\
\text { (Front), } \\
\text { cpm }\end{array}$ & $\begin{array}{c}\text { Alpha } \\
\text { (Back), } \\
\text { cpm }\end{array}$ & $\begin{array}{l}\text { Beta/Gamma } \\
\text { (Front), cpm }\end{array}$ & $\begin{array}{c}\text { Beta/Gamma } \\
\text { (Back), cpm }\end{array}$ & $\begin{array}{c}\text { Alpha } \\
\text { (Front), } \\
\text { cpm }\end{array}$ & $\begin{array}{c}\text { Alpha } \\
\text { (Back), } \\
\text { cpm }\end{array}$ & $\begin{array}{l}\text { Beta/Gamma } \\
\text { (Front), cpm }\end{array}$ & $\begin{array}{c}\text { Beta/Gamma } \\
\text { (Back), cpm }\end{array}$ & $\begin{array}{c}\text { Percent } \\
\text { Reduction }\end{array}$ \\
\hline $4-01$ & $\mathrm{AW101}$ & black film & 50 & 80 & $>100000$ & $>100000$ & 0 & 25 & 75000 & 70000 & $>27.6$ \\
\hline $4-02$ & AW101 & black film & 50 & 50 & $>100000$ & $>100000$ & 25 & 25 & 30000 & 65000 & $>52.8$ \\
\hline $6-01$ & AW101 & brown film & 25 & 25 & $>100000$ & $>100000$ & 50 & 25 & 40000 & 8000 & $>76.4$ \\
\hline $6-02$ & AW101 & brown film & 50 & 50 & $>100000$ & $>100000$ & 0 & 25 & 8000 & 50000 & $>71.4$ \\
\hline $4-09$ & $\mathrm{C} 104$ & black film & 100 & 100 & 95000 & 70000 & 50 & 25 & 700 & 1000 & 99.6 \\
\hline $4-10$ & $\mathrm{C} 104$ & black film & 100 & 150 & 85000 & 65000 & 50 & 50 & 900 & 700 & 99.6 \\
\hline $6-09$ & $\mathrm{C} 104$ & brown film & 150 & 100 & 80000 & 80000 & 25 & 25 & 750 & 1000 & 99.5 \\
\hline $6-10$ & C104 & brown film & 100 & 100 & 40000 & 60000 & 50 & 50 & 1000 & 1000 & 99.0 \\
\hline $4-17$ & AN107 & shiny & 100 & 50 & 40000 & $>100000$ & 25 & 25 & 800 & 900 & $>99.5$ \\
\hline $4-18$ & AN107 & shiny & 50 & 100 & 30000 & 25000 & 50 & 25 & 950 & 950 & 98.3 \\
\hline $6-17$ & AN107 & shiny & 100 & 150 & 40000 & 50000 & 50 & 50 & 900 & 800 & 99.2 \\
\hline $6-18$ & AN107 & shiny & 100 & 100 & 100000 & 60000 & 25 & 50 & 700 & 900 & 99.6 \\
\hline
\end{tabular}


Table 5. Plate-Out Deposit Removal During the Decontamination Test

\begin{tabular}{|c|c|c|c|c|}
\hline $\begin{array}{c}\text { Specimen } \\
\text { Serial \# }\end{array}$ & Waste Solution & $\begin{array}{c}\text { Weight Loss After } \\
\text { Plate-Out Test, g }\end{array}$ & $\begin{array}{c}\text { Total Weight Loss } \\
\text { After CP-9, g }\end{array}$ & $\begin{array}{c}\text { \% Deposit } \\
\text { Removed by } \\
\text { 1 M HNO3 }\end{array}$ \\
\hline $4-01$ & AW101 & 0.0060 & 0.0093 & 64.5 \\
\hline $4-02$ & AW101 & 0.0065 & 0.0100 & 65.0 \\
\hline $6-01$ & AW101 & 0.0098 & 0.0138 & 71.0 \\
\hline $6-02$ & AW101 & 0.0158 & 0.0192 & 82.3 \\
\hline $4-09$ & C104 & 0.0096 & 0.0134 & 71.6 \\
\hline $4-10$ & C104 & 0.0093 & 0.0137 & 67.9 \\
\hline $6-09$ & C104 & 0.0152 & 0.0167 & 91.0 \\
\hline $6-10$ & C104 & 0.0142 & 0.0164 & 86.6 \\
\hline $4-17$ & AN107 & 0.1464 & 0.1486 & 98.5 \\
\hline $4-18$ & AN107 & 0.0805 & 0.0830 & 97.0 \\
\hline $6-17$ & AN107 & 0.0367 & 0.0364 & 100.8 \\
\hline $6-18$ & AN107 & 0.1634 & 0.1646 & 99.3 \\
\hline
\end{tabular}


Table 6. 304L Corrosion Data

\begin{tabular}{|c|c|c|c|c|c|}
\hline \multirow{2}{*}{ Serial\# } & \multirow{2}{*}{ Solution } & Location & Appearance Before & \multicolumn{2}{|c|}{ Corrosion Rate } \\
\cline { 5 - 6 } & & & Cleaning & mpy & mm/y \\
\hline $4-01$ & AW-101 & liquid & black film & 0.353 & 0.00897 \\
\hline $4-02$ & AW-101 & liquid & black film & 0.389 & 0.00988 \\
\hline $4-03$ & AW-101 & liquid/vapor & black deposit & 0.605 & 0.01536 \\
\hline $4-04$ & AW-101 & liquid/vapor & black deposit & 0.505 & 0.01282 \\
\hline $4-05$ & AW-101 & vapor (a) & thin black & 0.367 & 0.00932 \\
\hline $4-06$ & AW-101 & vapor (a) & thin black & 0.358 & 0.00909 \\
\hline $4-07$ & AW-101 & vapor (b) & thin black & 0.234 & 0.00593 \\
\hline $4-08$ & AW-101 & vapor (b) & thin black & 0.242 & 0.00615 \\
\hline $4-09$ & C-104 & liquid & black film & 0.284 & 0.00721 \\
\hline $4-10$ & C-104 & liquid & black film & 0.286 & 0.00726 \\
\hline $4-11$ & C-104 & liquid/vapor & thin yellow deposit & 0.281 & 0.00714 \\
\hline $4-12$ & C-104 & liquid/vapor & thin yellow deposit & 0.274 & 0.00695 \\
\hline $4-13$ & C-104 & vapor (a) & thin black & 0.244 & 0.00620 \\
\hline $4-14$ & C-104 & vapor (a) & thin black & 0.276 & 0.00702 \\
\hline $4-15$ & C-104 & vapor (b) & shiny & 0.206 & 0.00523 \\
\hline $4-16$ & C-104 & vapor (b) & shiny & 0.193 & 0.00490 \\
\hline $4-17$ & AN-107 & liquid & shiny & 0.197 & 0.00500 \\
\hline $4-18$ & AN-107 & liquid & shiny & 0.205 & 0.00521 \\
\hline $4-19$ & AN-107 & liquid/vapor & white deposit & 0.253 & 0.00644 \\
\hline $4-20$ & AN-107 & liquid/vapor & white deposit & 0.251 & 0.00637 \\
\hline $4-21$ & AN-107 & vapor (a) & straw color & 0.187 & 0.00476 \\
\hline $4-22$ & AN-107 & vapor (a) & straw color & 0.215 & 0.00547 \\
\hline $4-23$ & AN107 & vapor (b) & straw color & 0.222 & 0.00564 \\
\hline $4-24$ & AN107 & vapor (b) & straw color & 0.209 & 0.00530 \\
\hline
\end{tabular}

(a) vapor space-non-condensing.

(b) vapor space - condensing. 
Table 7. 316L Corrosion Data

\begin{tabular}{|c|c|c|c|c|c|}
\hline \multirow{2}{*}{$\begin{array}{l}\text { Specimen } \\
\text { Serial \# }\end{array}$} & \multirow{2}{*}{ Solution } & \multirow{2}{*}{ Location } & \multirow{2}{*}{$\begin{array}{c}\text { Appearance } \\
\text { Before Cleaning }\end{array}$} & \multicolumn{2}{|c|}{ Corrosion Rate } \\
\hline & & & & mpy & $\mathrm{mm} / \mathbf{y}$ \\
\hline $6-01$ & AW101 & liquid & brown film & 0.272 & 0.00690 \\
\hline $6-02$ & AW101 & liquid & brown film & 0.250 & 0.00635 \\
\hline $6-03$ & AW101 & liquid/vapor & thin yellow deposit & 0.473 & 0.01201 \\
\hline $6-04$ & AW101 & liquid/vapor & thin yellow deposit & 0.591 & 0.01500 \\
\hline $6-05$ & AW101 & vapor (a) & thin black & 0.111 & 0.00281 \\
\hline $6-06$ & AW101 & vapor (a) & thin black & 0.555 & 0.01410 \\
\hline $6-07$ & AW101 & vapor (b) & thin black & 0.070 & 0.00177 \\
\hline $6-08$ & AW101 & vapor (b) & thin black & 0.056 & 0.00143 \\
\hline $6-09$ & C104 & liquid & brown film & 0.132 & 0.00335 \\
\hline $6-10$ & $\mathrm{C} 104$ & liquid & brown film & 0.155 & 0.00394 \\
\hline $6-11$ & C104 & liquid/vapor & thin yellow deposit & 0.117 & 0.00296 \\
\hline $6-12$ & $\mathrm{Cl04}$ & liquid/vapor & thin yellow deposit & 0.134 & 0.00341 \\
\hline $6-13$ & $\mathrm{ClO4}$ & vapor (a) & thin black & 0.122 & 0.00311 \\
\hline $6-14$ & $\mathrm{ClO4}$ & vapor (a) & thin black & 0.146 & 0.00370 \\
\hline $6-15$ & $\mathrm{Cl04}$ & vapor (b) & shiny & 0.043 & 0.00108 \\
\hline $6-16$ & $\mathrm{C104}$ & vapor (b) & shiny & 0.047 & 0.00119 \\
\hline $6-17$ & AN107 & liquid & shiny & 0.035 & 0.00089 \\
\hline $6-18$ & AN107 & liqquid & Shiny & 0.051 & 0.00129 \\
\hline $6-19$ & AN107 & liquid/vapor & white deposit & 0.168 & 0.00427 \\
\hline $6-20$ & AN107 & liquid/vapor & white deposit & 0.134 & 0.00340 \\
\hline $6-21$ & AN107 & vapor (a) & straw color & 0.080 & 0.00202 \\
\hline $6-22$ & AN107 & vapor (a) & straw color & 0.089 & 0.00226 \\
\hline $6-23$ & AN107 & vapor (b) & straw color & 0.045 & 0.00114 \\
\hline $6-24$ & AN107 & vapor (b) & straw color & 0.056 & 0.00143 \\
\hline
\end{tabular}

(a) vapor space-non-condensing.

(b) vapor space - condensing. 


\subsection{References}

ASTM-G-1-90, Standard Practice for Preparing, Cleaning, and Evaluating Corrosion Test Specimens, 1998 Annual Book of ASTM Standards, volume 03.02 - Wear and Erosion; Metal Corrosion. American Society of Testing and Materials, Philadelphia, Pennsylvania.

ASTM-G-31-72, Standard Practice for Laboratory Immersion Corrosion Testing of Metals, 1998 Annual Book of ASTM Standards, volume 03.02 - Wear and Erosion; Metal Corrosion, American Society of Testing and Materials, Philadelphia, Pennsylvania.

Danielson, M. J. and S. G. Pitman. February 2000. "Corrosion Tests of 316L and Hastelloy C-22 in Simulated Tank Waste Solutions." PNWD-3015, BNFL-RPT-019, Battelle, Richland Washington.

Johnson, M. E. August 24, 1999. "Materials Corrosion, Erosion, and Plate-Out Test Specification." Revision 2. TSP-W375-99-00001. River Protection Project - Waste Treatment Plant. BNFL, Inc. Richland, Washington. 


$$
\begin{aligned}
& \frac{7}{8} \\
& \frac{0}{0} \\
& \frac{1}{3} \\
& \frac{2}{x} \\
& D
\end{aligned}
$$




\section{Appendix A: Photographs from Corrosion and Decontamination Tests}




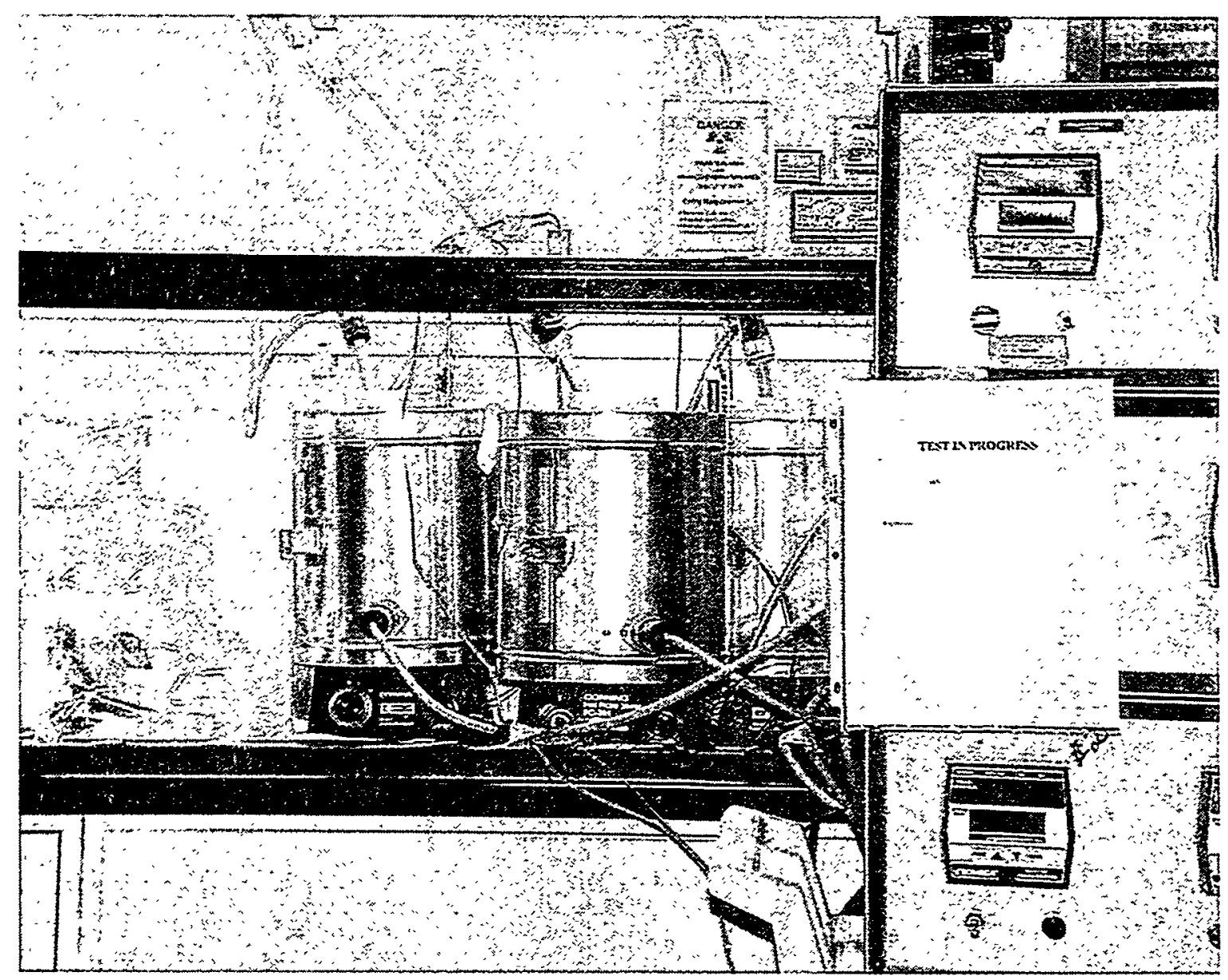

Figure A.1. Test Apparatus Set Up in the Contamination Area Hood 


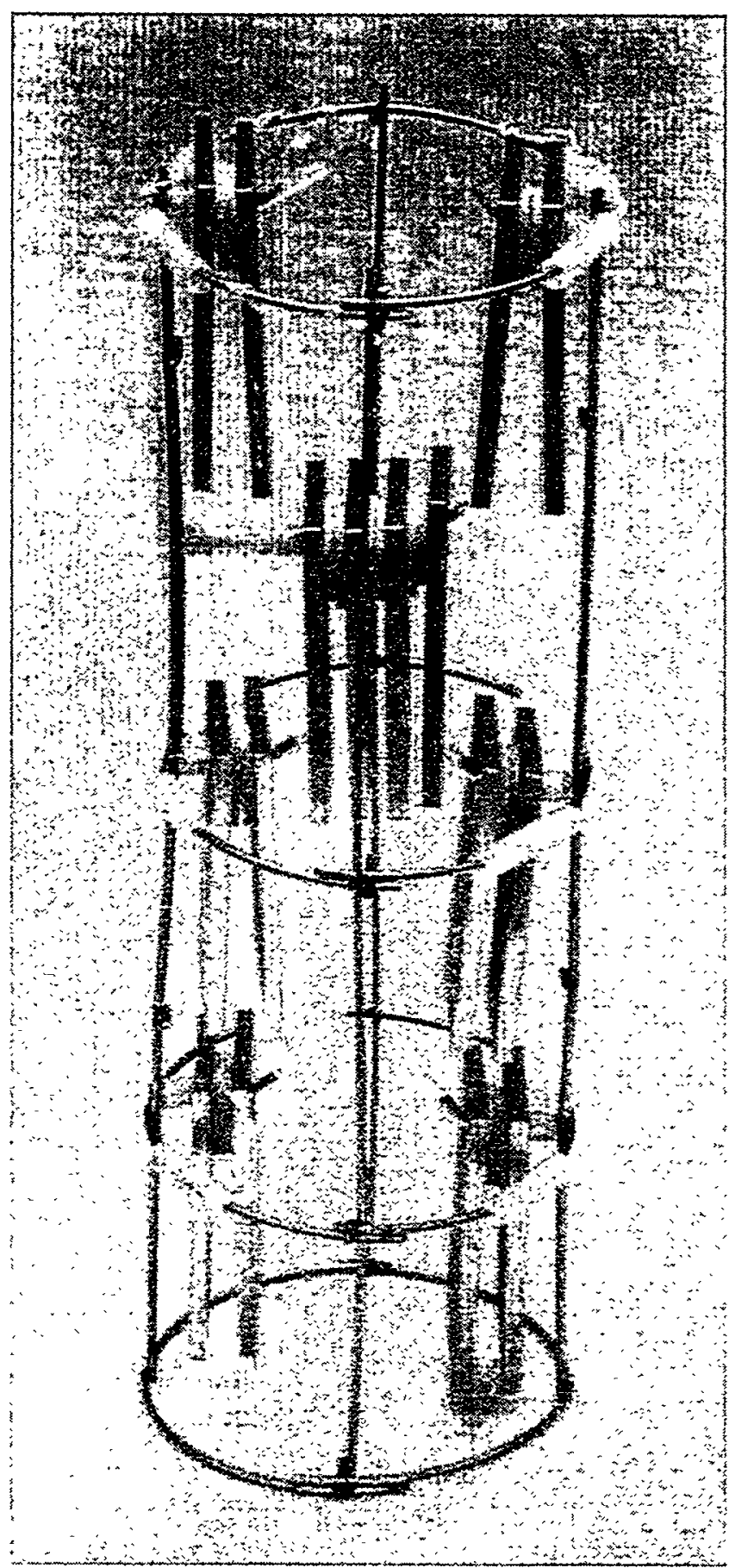

Figure A.2. Rack with 304L and 316L Specimens 


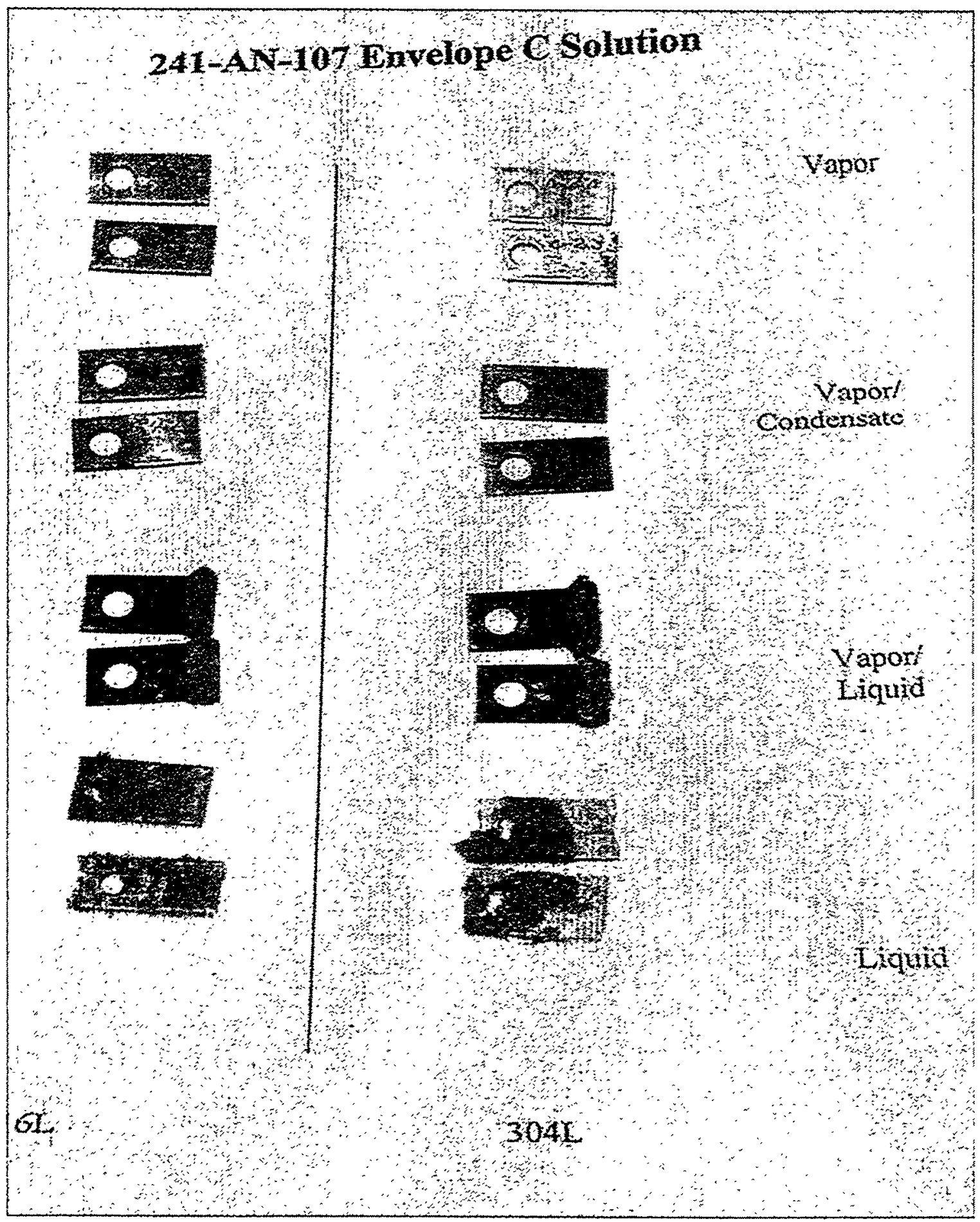

Figure A.3. Specimens After Removal From AN-107 Solution (316L Specimens on Left) 


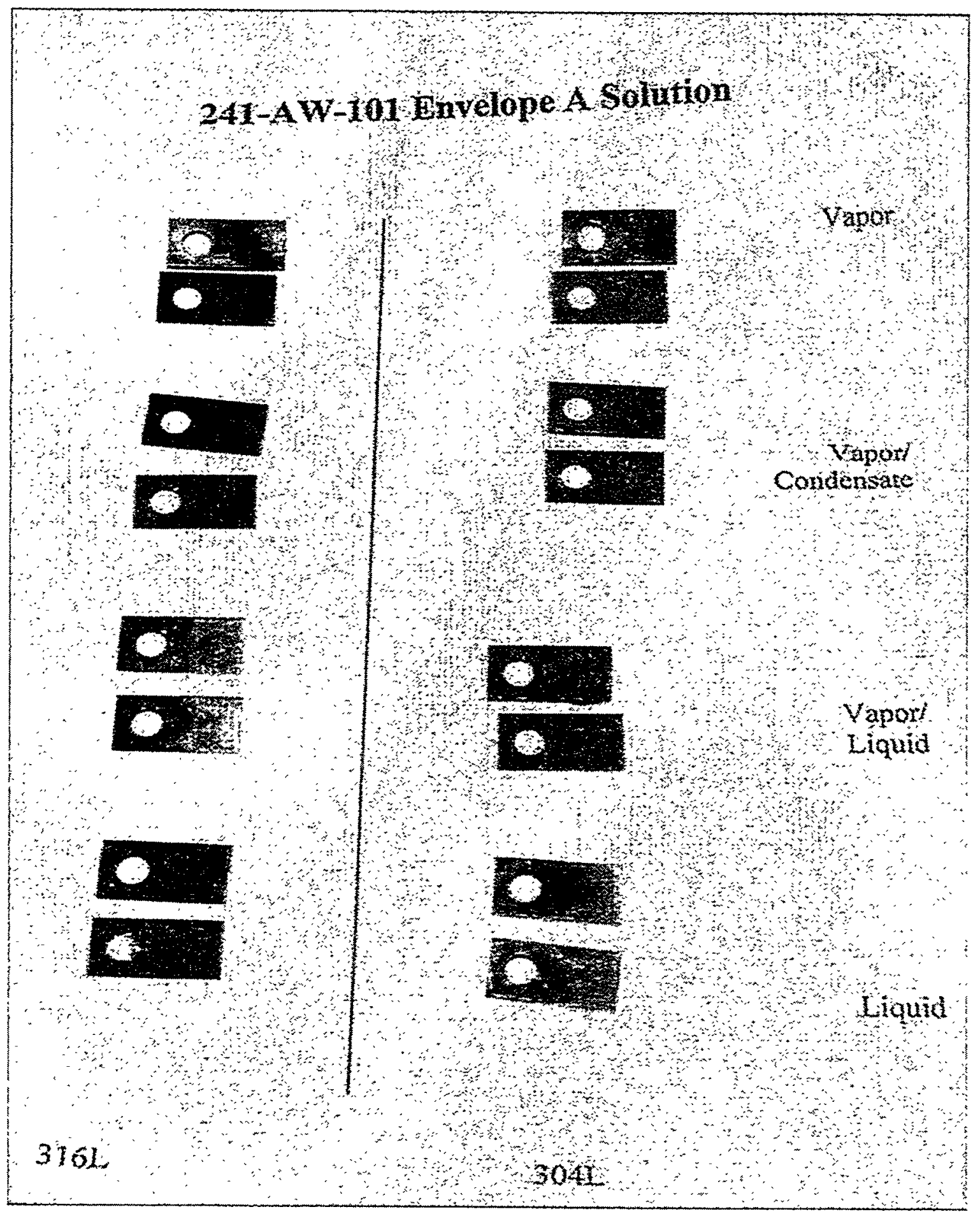

Figure A.4. Specimens After Removal From AW-101 Solution 


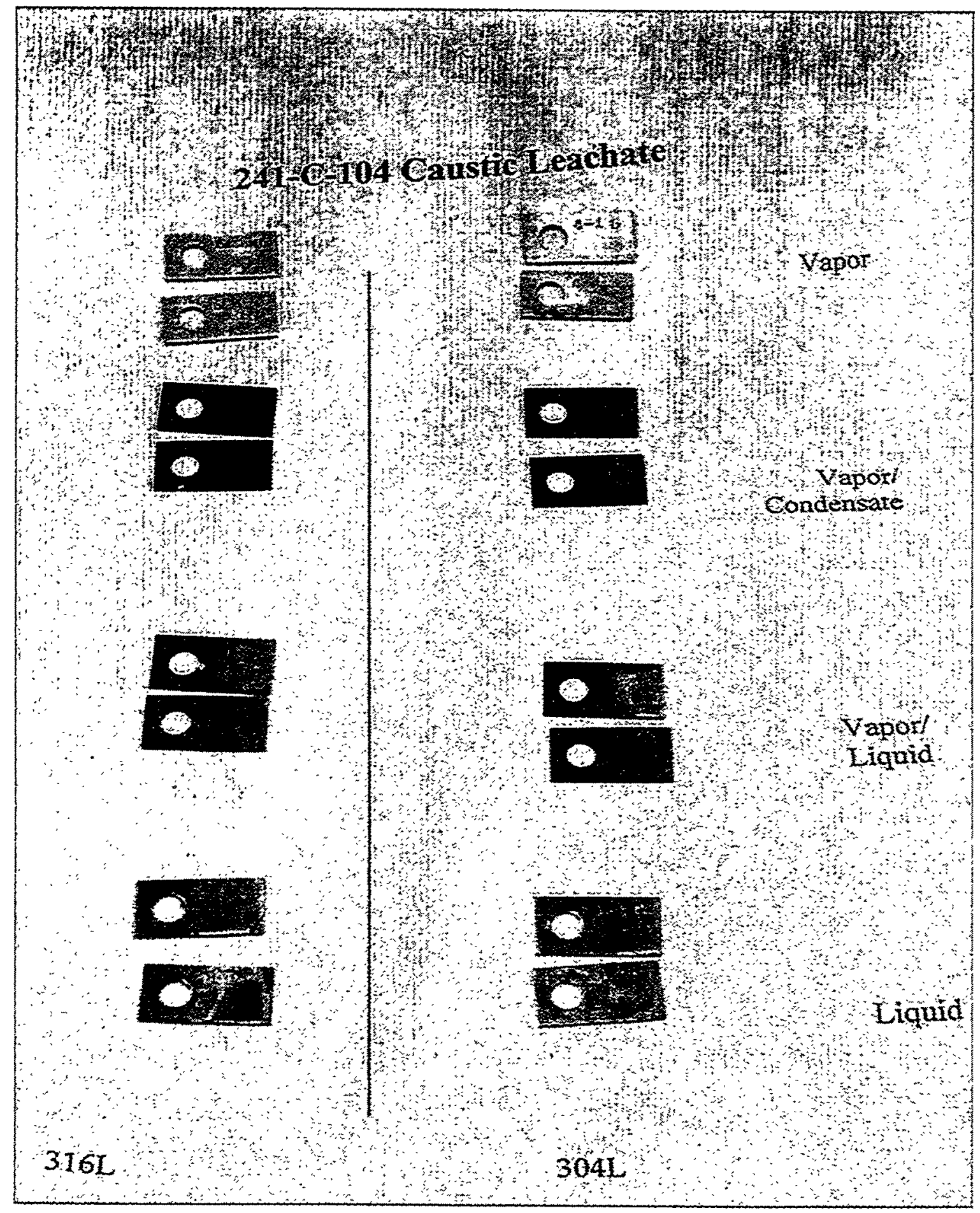

Figure A.5. Specimens After Removal From C-104 Solution 


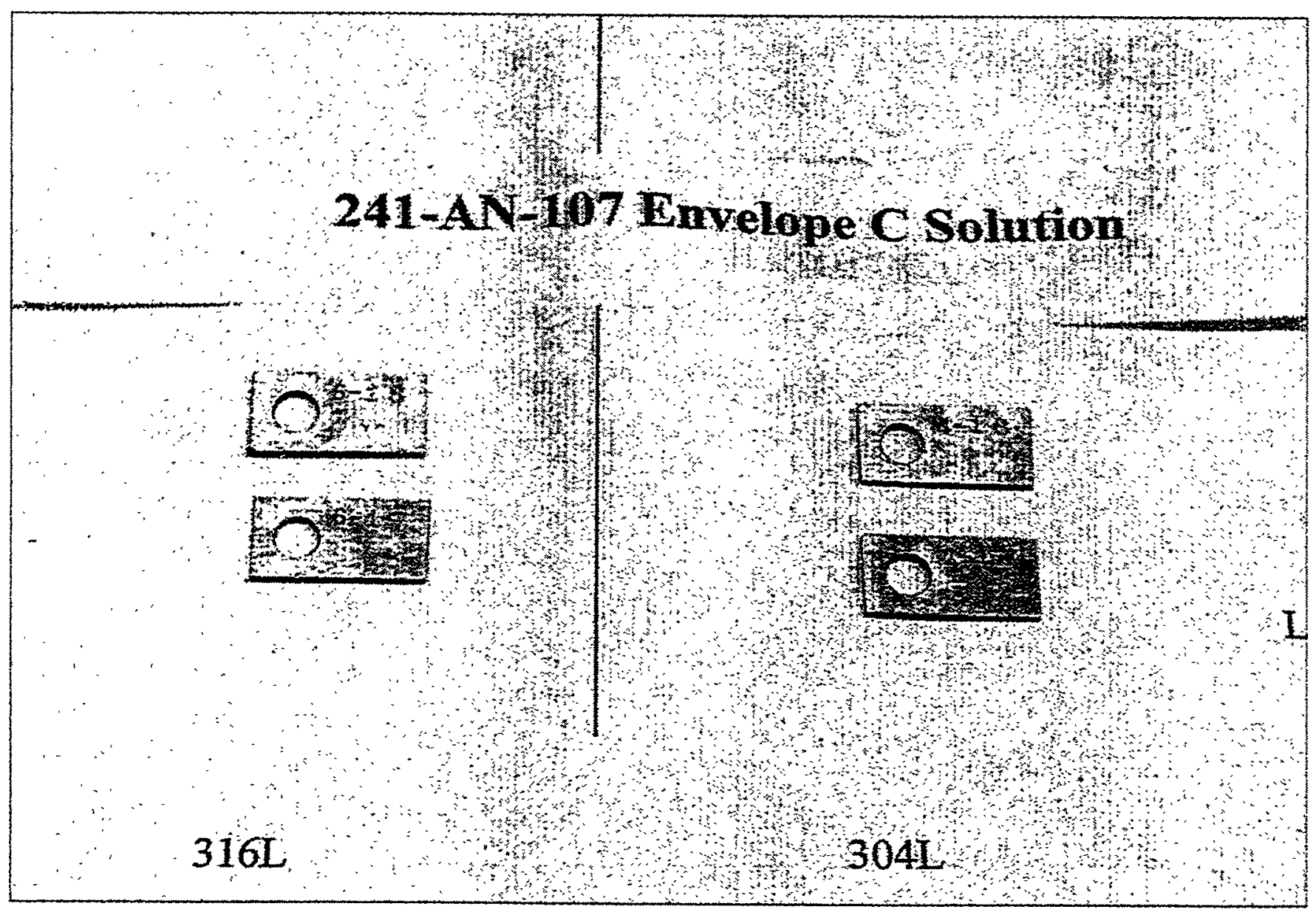

Figure A.6. AN-107 Specimens After Plate-Out Decontamination Tests 


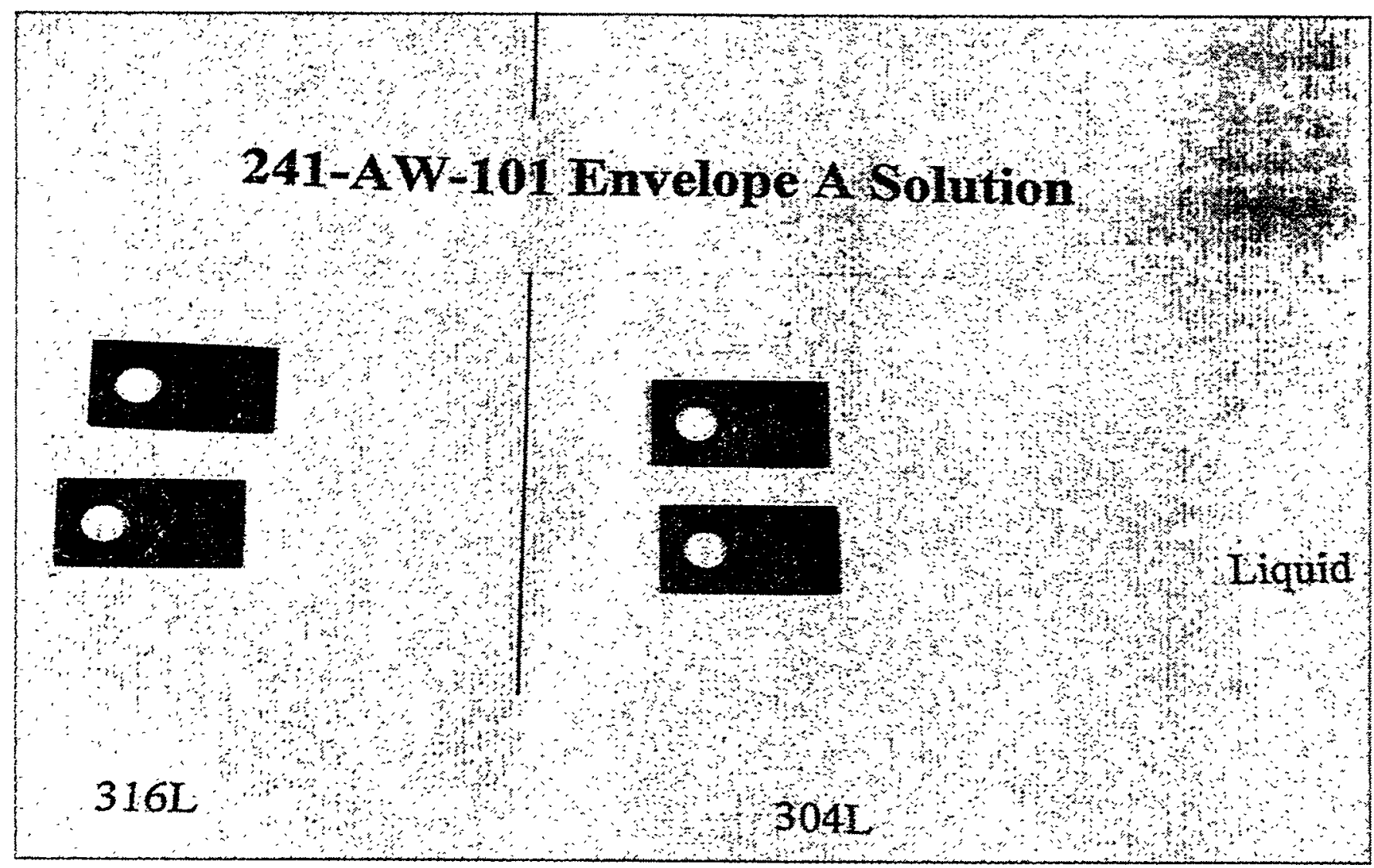

Figure A.7. AW-101 Specimens After Plate-Out Decontamination Tests 

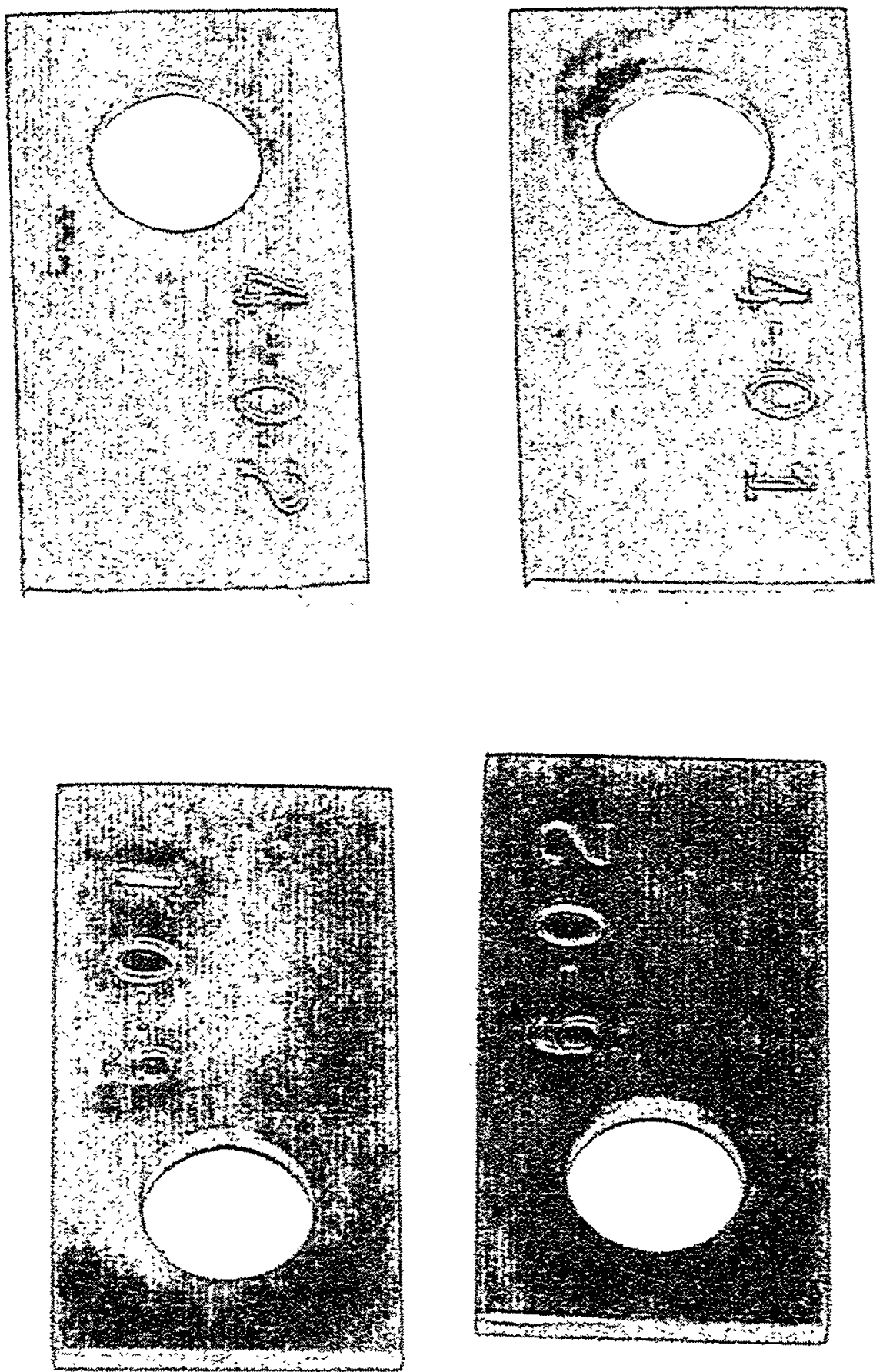

Figure A.8. Specimens from Liquid Phase Exposure - AW-101 Solution Following Final Cleaning (304L Top) 

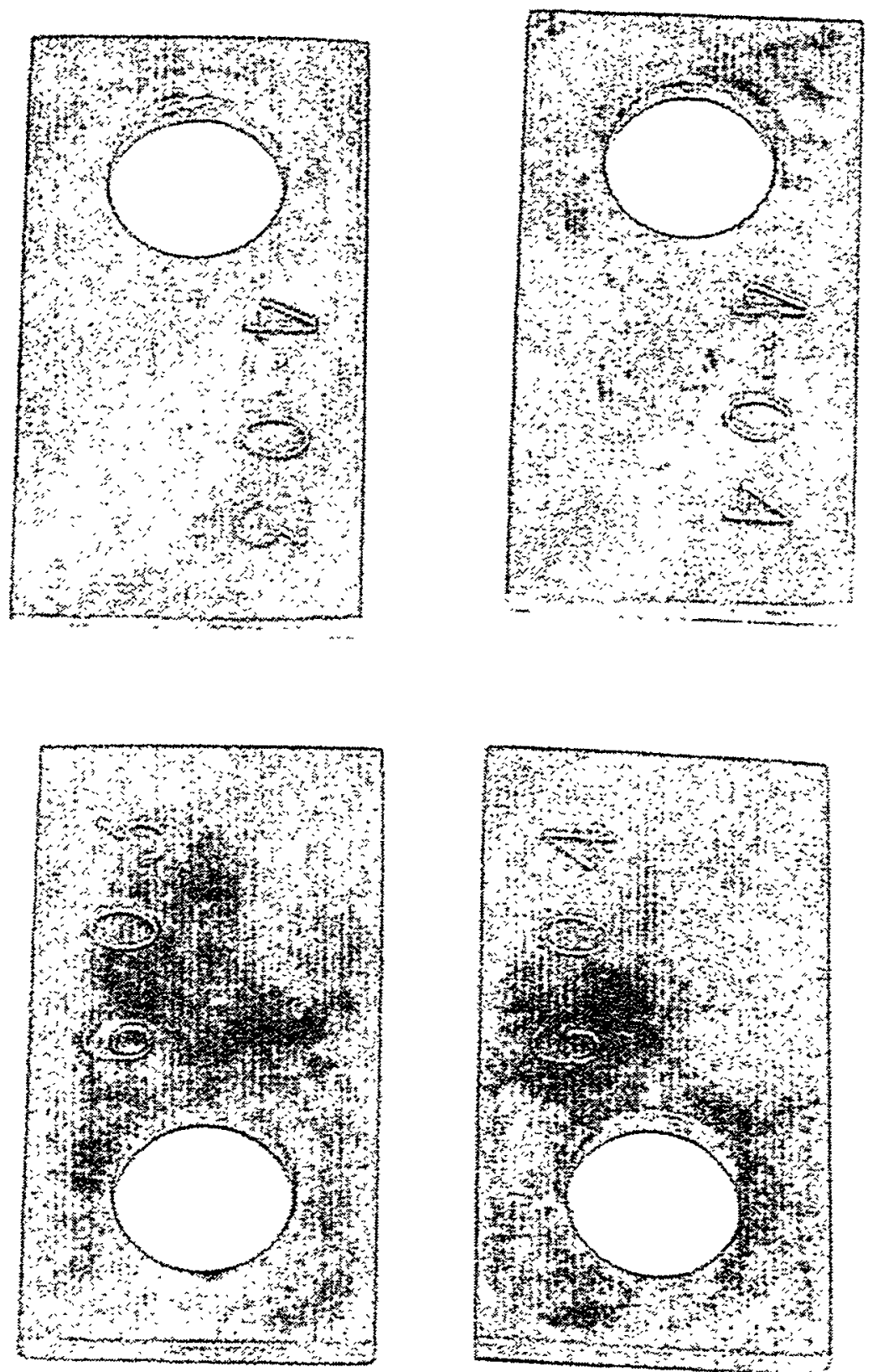

Figure A.9. Specimens from Liquid/Vapor Phase Exposure - AW-101 Solution Following Final Cleaning (304L Top Row) 

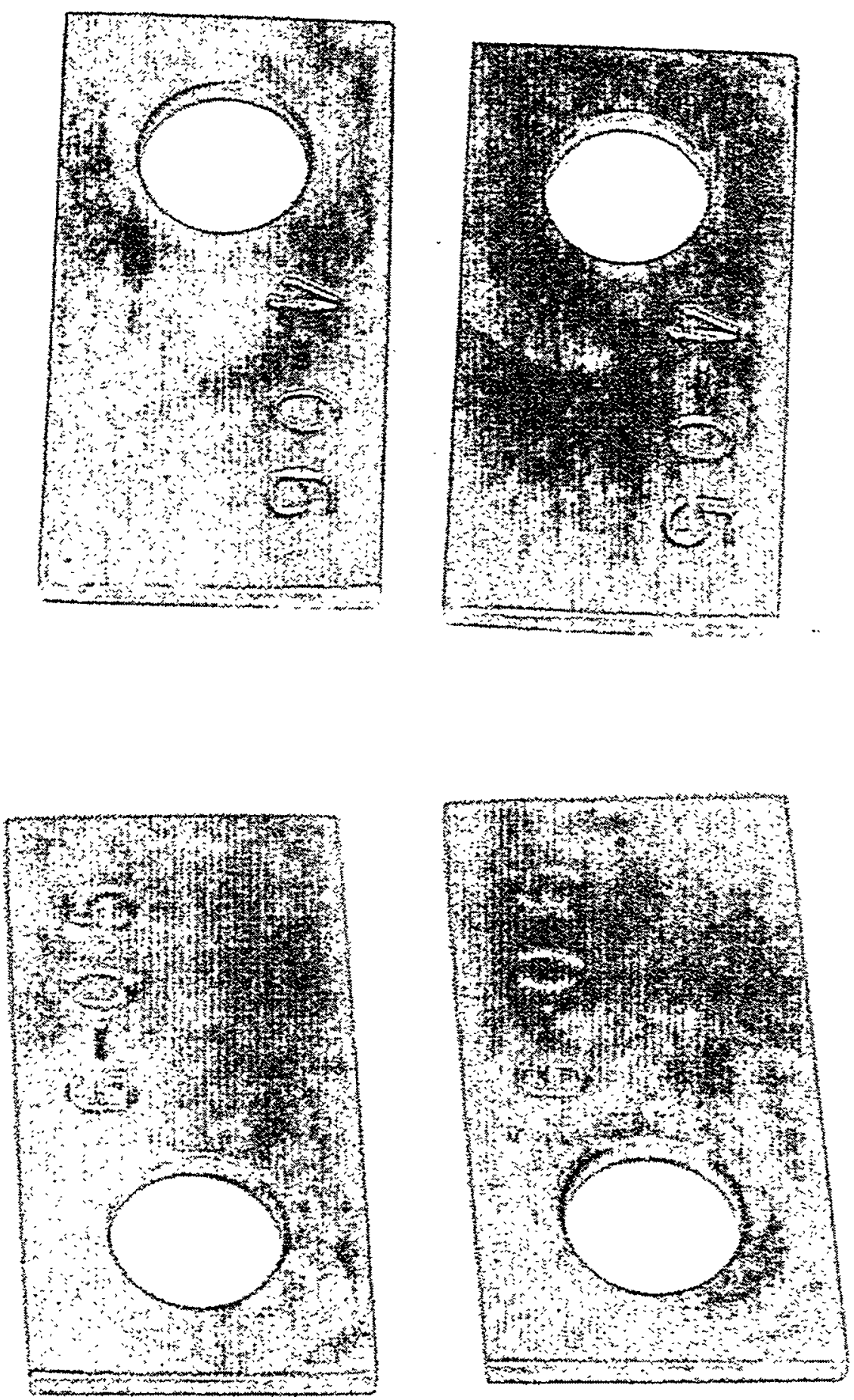

Figure A.10. Specimens from Vapor Phase (Noncondensing) Exposure - AW-101 Solution Following Final Cleaning (304L Top Row) 

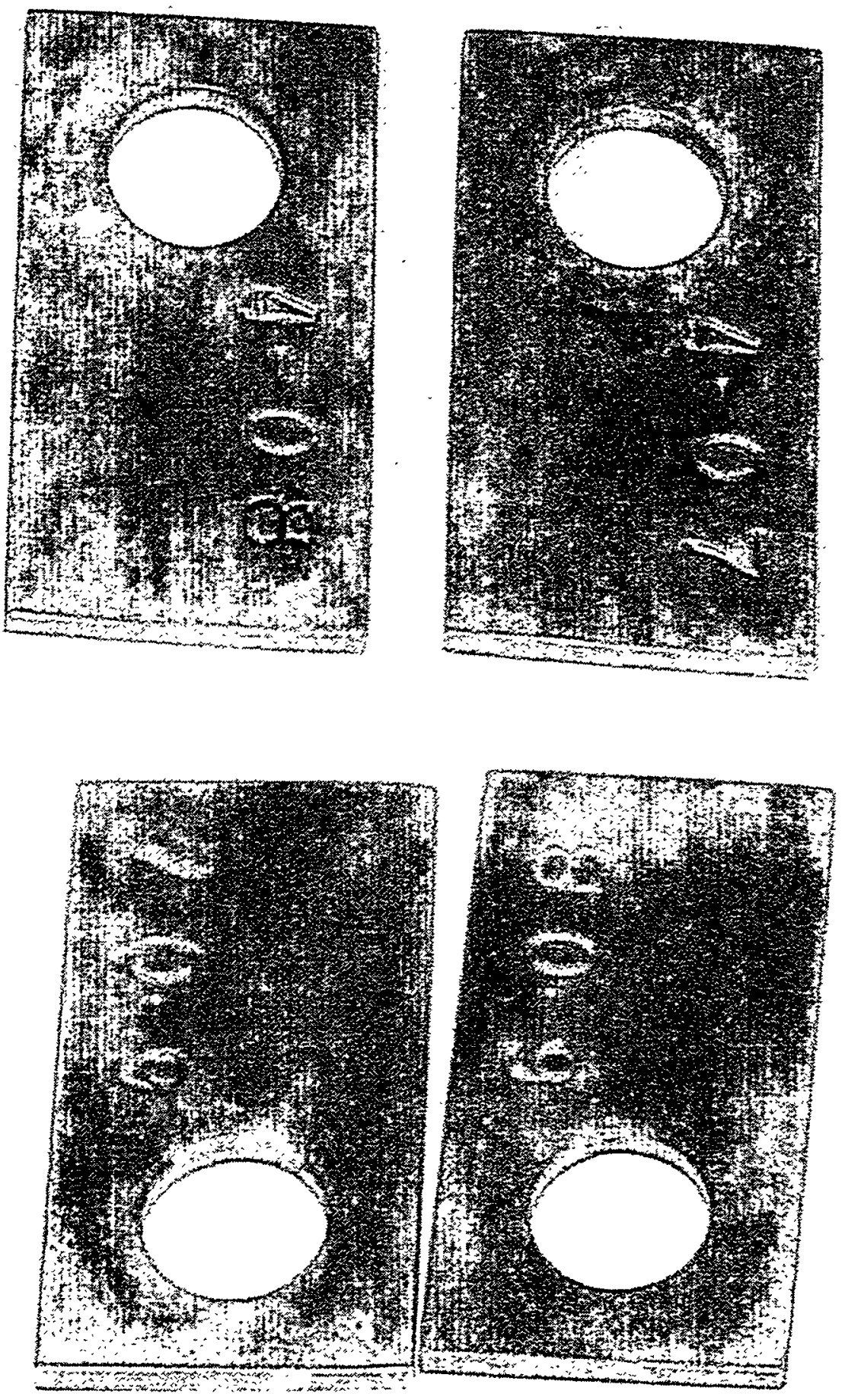

Figure A.11. Specimens from Vapor Phase (Condensing) Exposure - AW-101 Solution Following Final Cleaning (304I Top Row) 

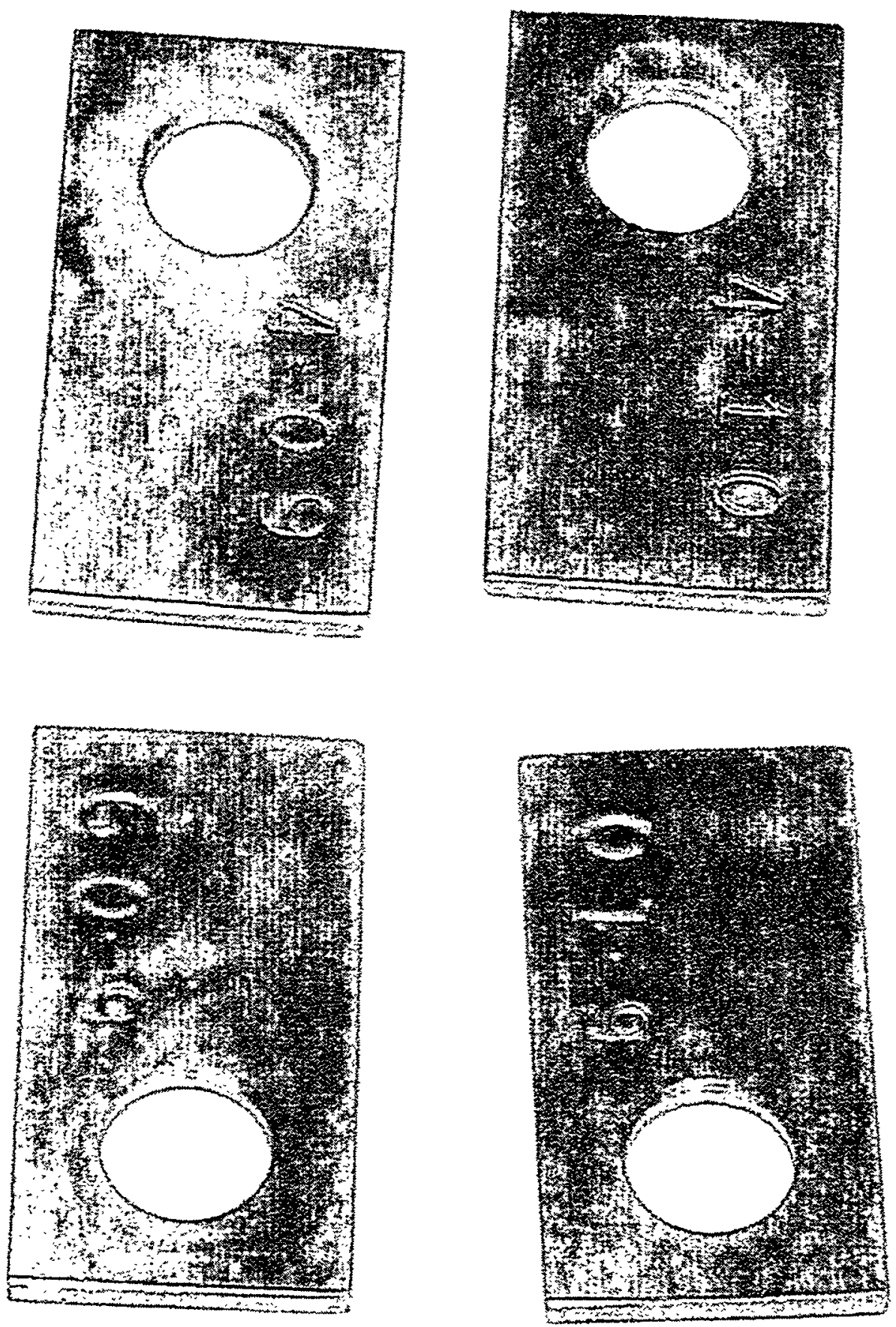

Figure A.12. Specimens from Liquid Phase Exposure - C-104 Solution Following Final Cleaning (304L Top Row) 

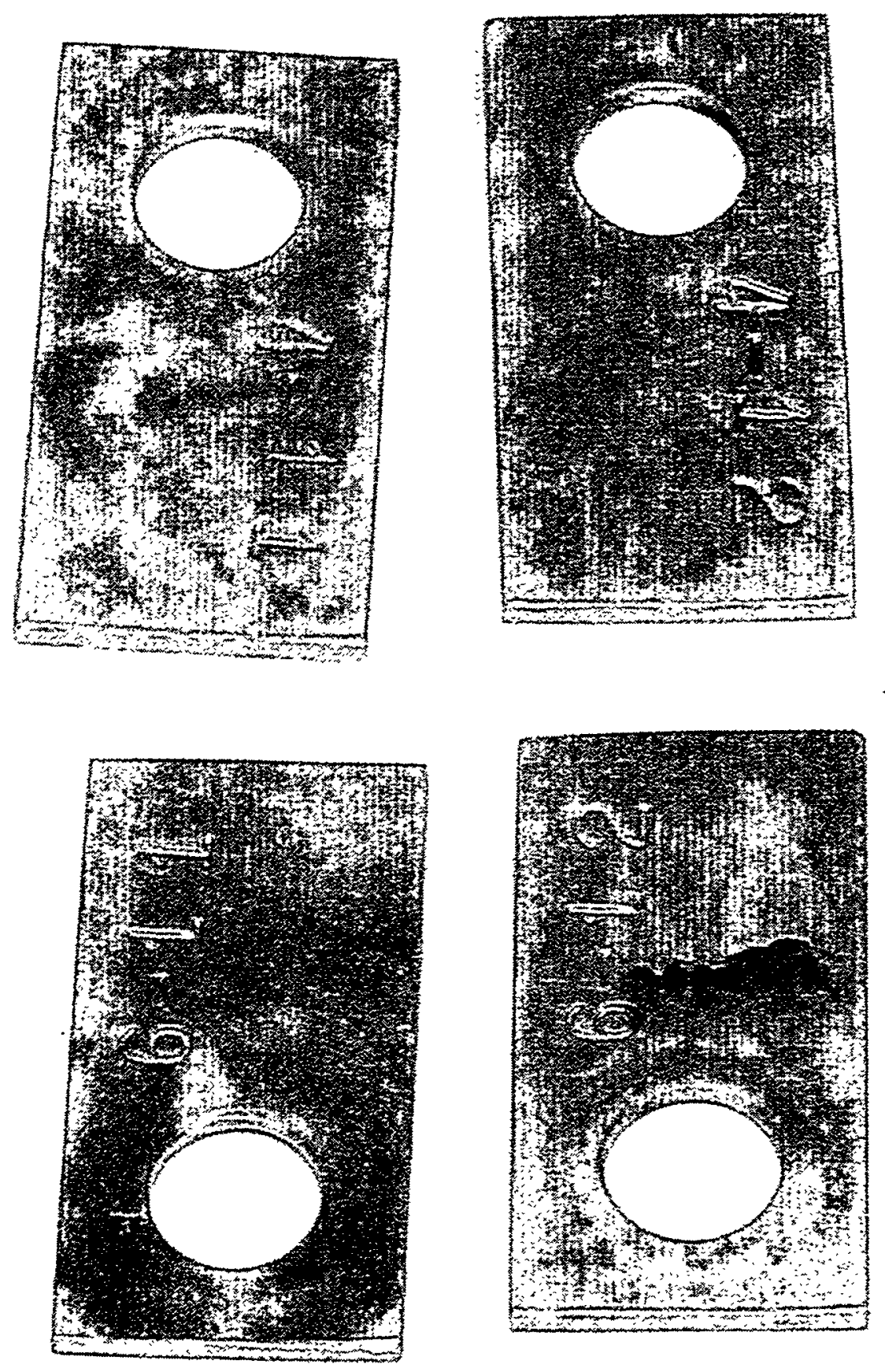

Figure A.13. Specimens from Liquid/Vapor Phase Exposure - C-104 Solution Following Final Cleaning (304L Top Row) 

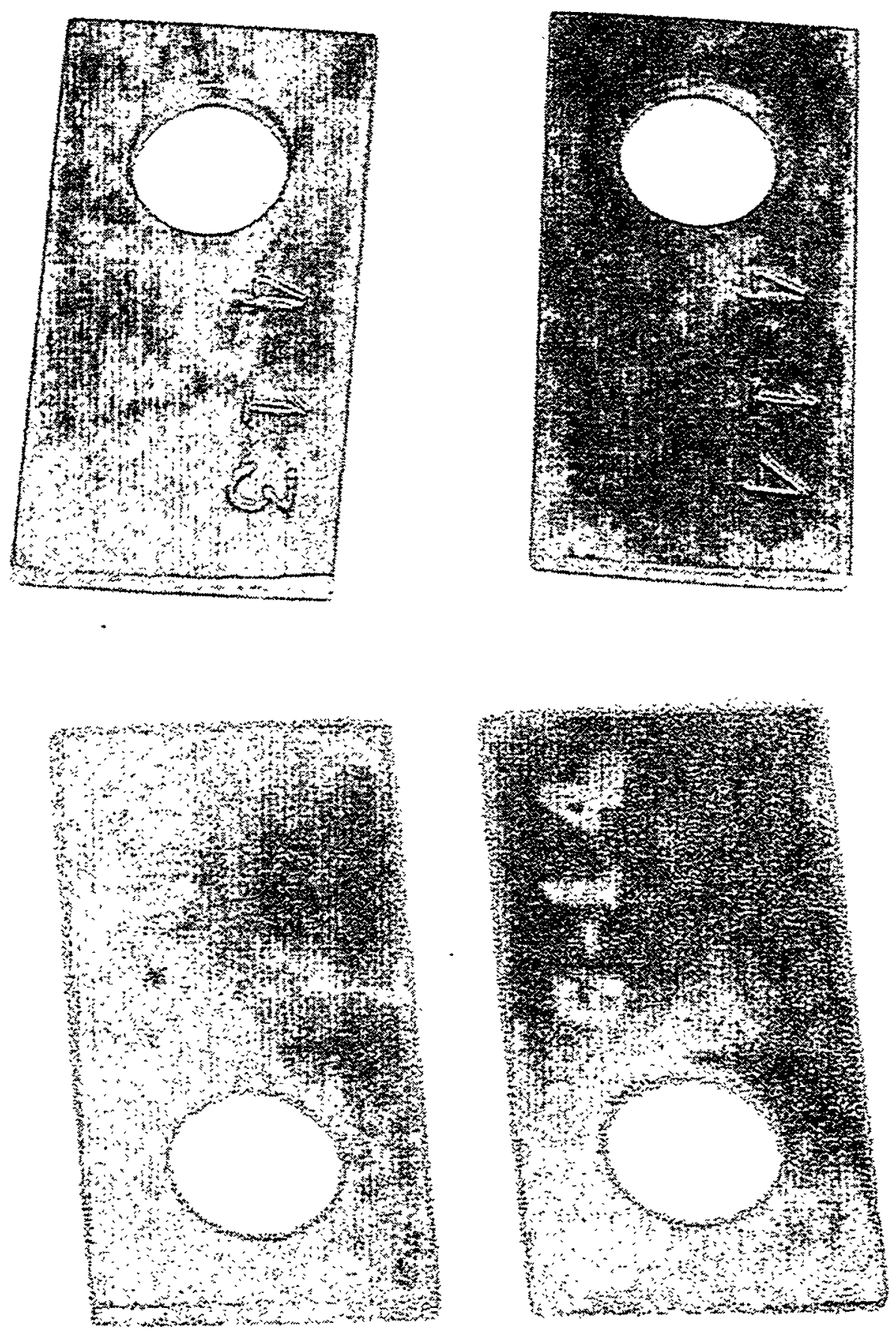

Figure A.14. Specimens from Vapor Phase (Noncondensing) Exposure - C-104 Solution Following Final Cleaning (304L Top Row) 

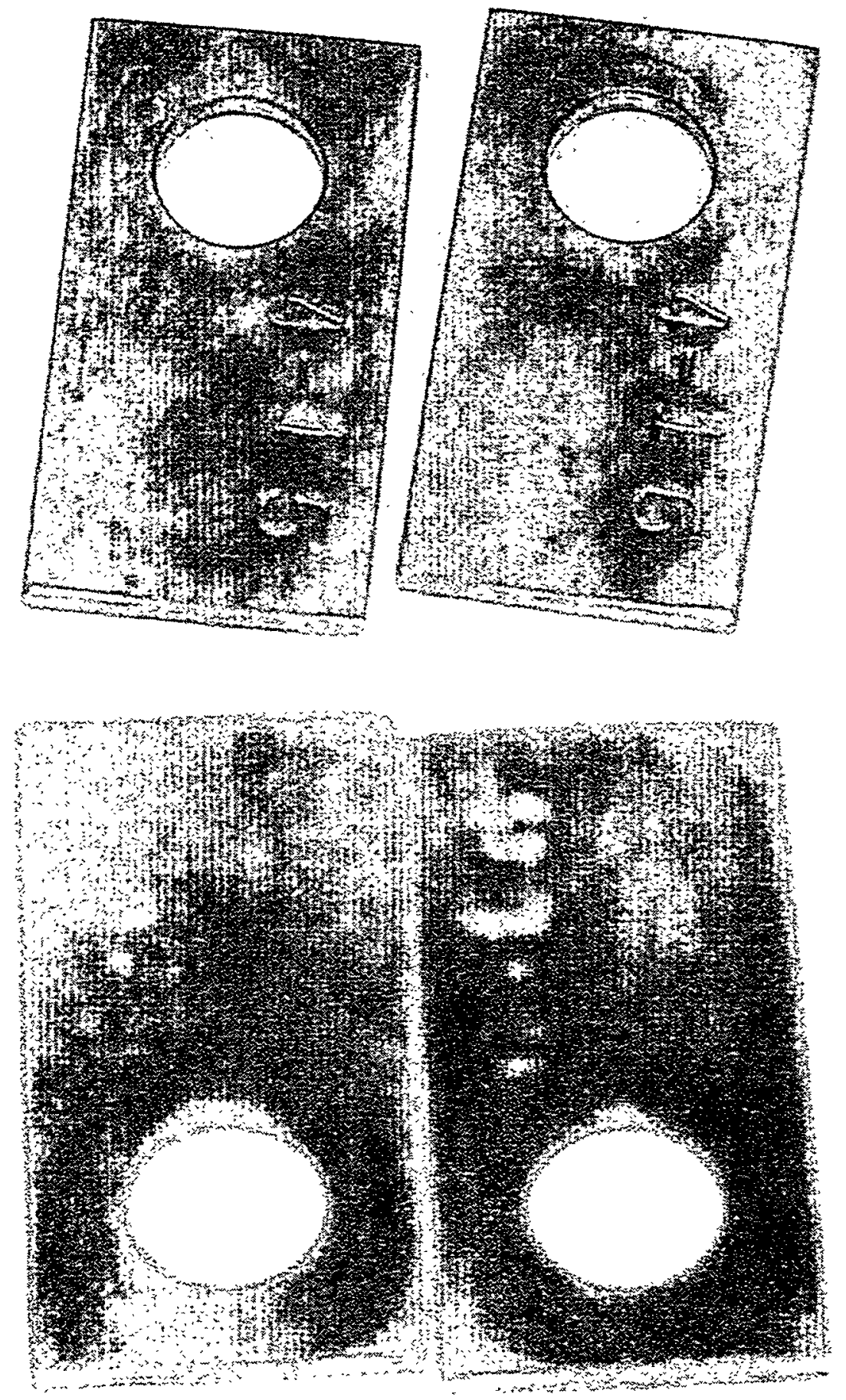

Figure A.15. Specimens from Vapor Phase (Condensing) Exposure - C-104 Solution Following Final Cleaning (304L Top Row) 

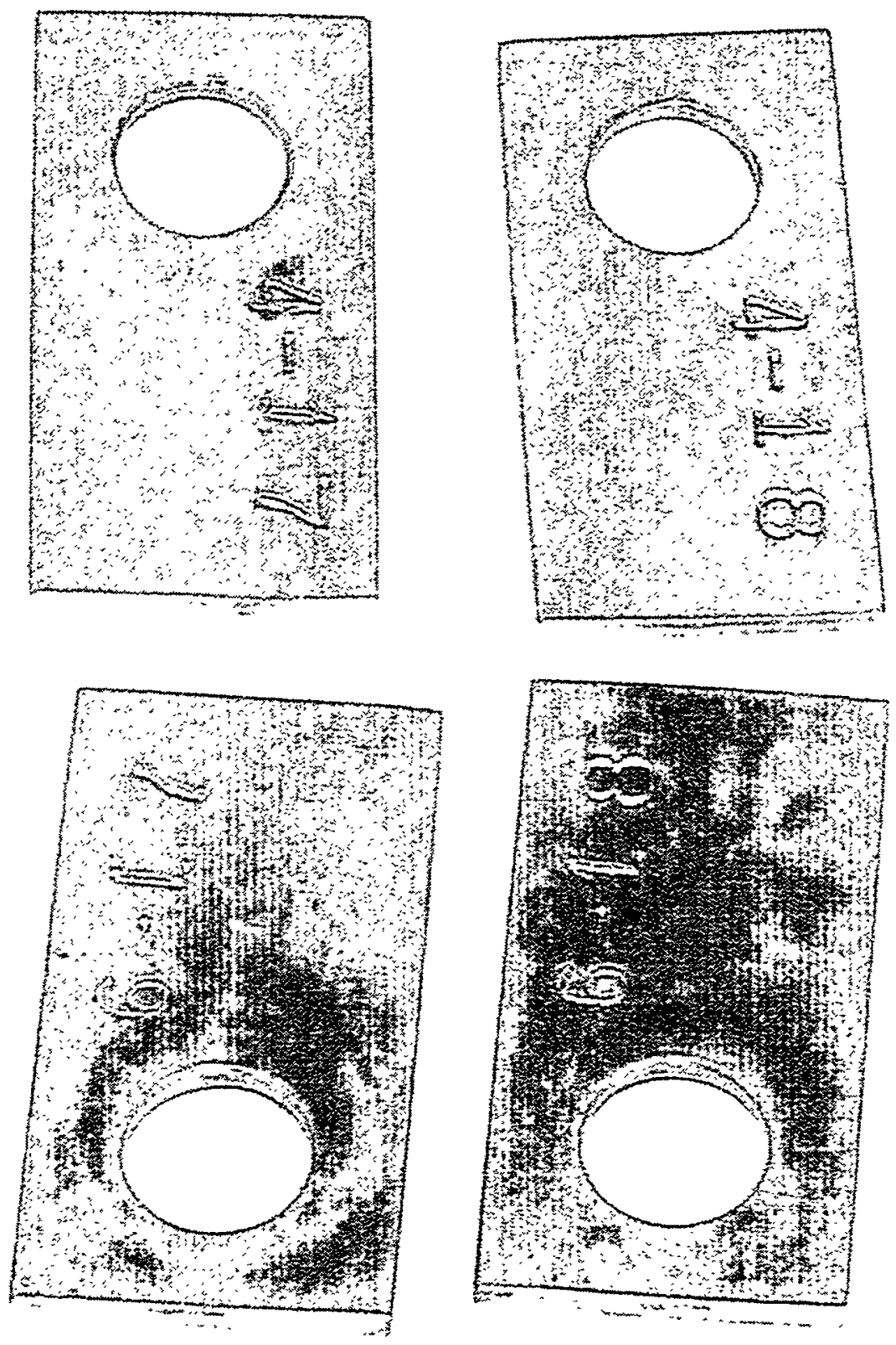

Figure A.16. Specimens from Liquid Phase Exposure - AN-107 Solution Following Final Cleaning (304L Top Row) 

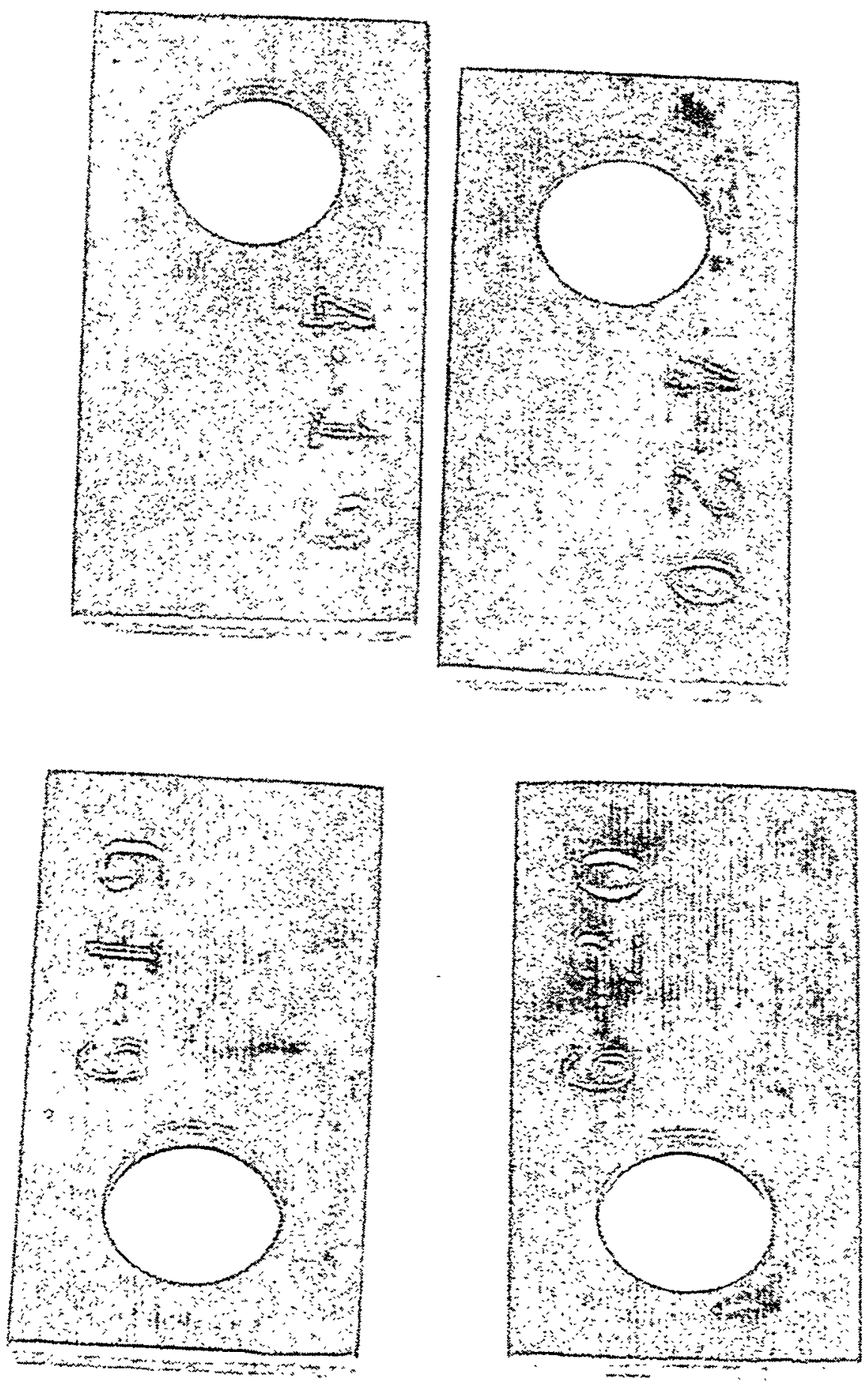

Figure A.17. Specimens from Liquid/Napor Phase Exposure - AN-107 Solution Following Final Cleaning (304L Top Row) 

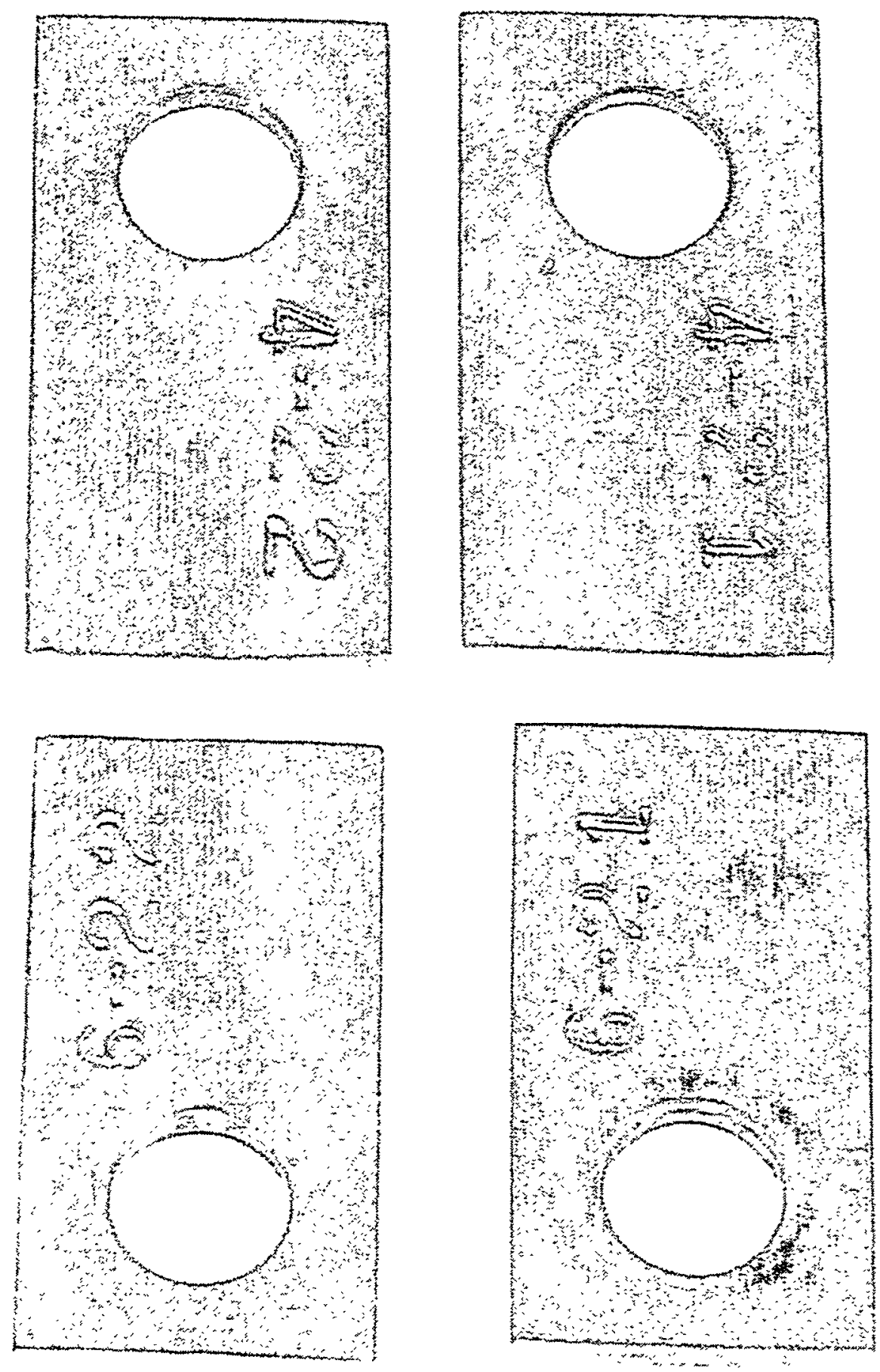

Figure A.18. Specimens from Vapor Phase (Noncondensing) Exposure - AN-107 Solution Following Final Cleaning (304L Top Row) 

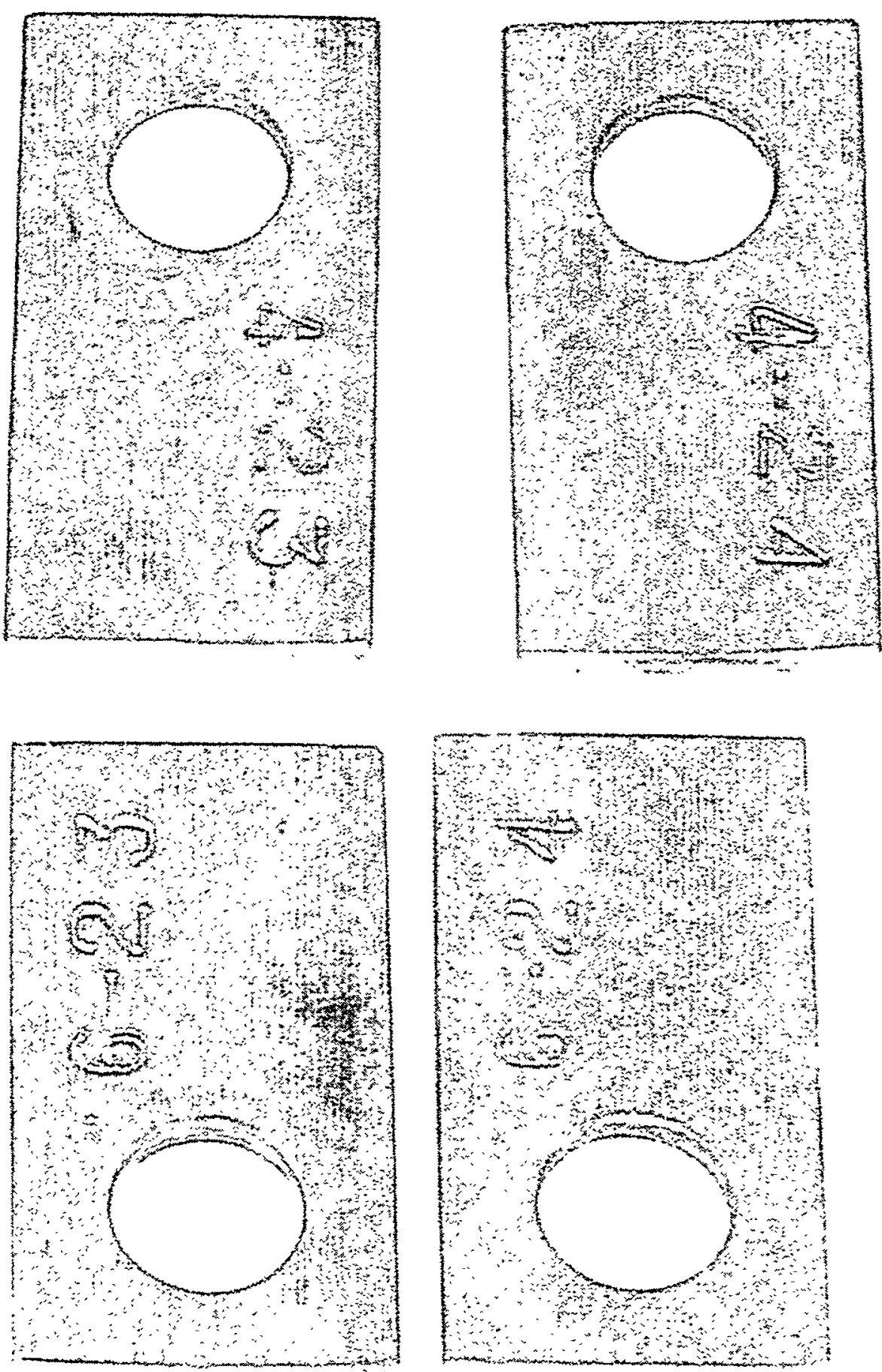

Figure A.19. Specimens from Vapor Phase (Condensing) Exposure - AN-107 Solution Following Final Cleaning (304L Top Row) 
PNWD-3051

BNFL-RPT-039, Rev. 0

\section{Distribution}

No. of

No. of

Copies

Copies

OFFSITE

ONSITE

2 DOE/Office of Scientific and Technical Information

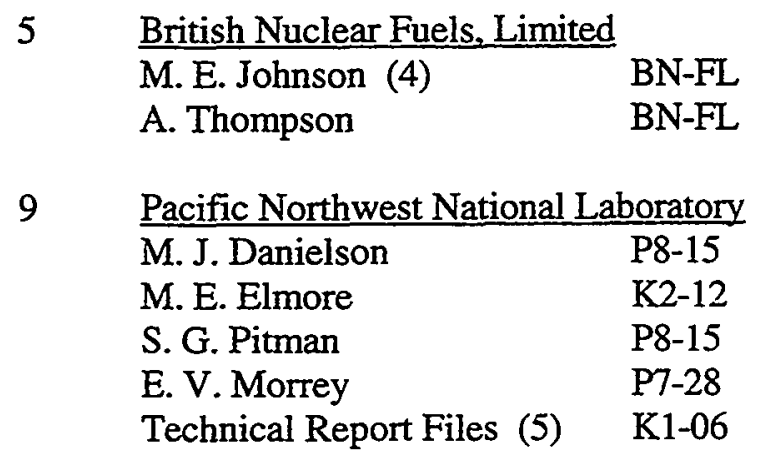

Distr. 1 